Motrivivência $\quad$ v. 28, n. 49, p. 71-81, dezembro/2016

\title{
POLÍTICAS PÚBLICAS DE MOBILIDADE URBANA E PRÁTICAS CORPORAIS: repercussões do sistema de bicicletas compartilhadas ${ }^{1}$
}

\author{
José Paulo Gurgel Teixeira² \\ Braulio Nogueira de Oliveira ${ }^{3}$ \\ Bérgson Nogueira de Oliveira ${ }^{4}$ \\ Wellington Gomes Feitosa ${ }^{5}$
}

\begin{abstract}
RESUMO
O estudo procurou analisar as percepções dos usuários quanto à implantação do projeto de bicicletas compartilhadas em Fortaleza, Ceará. Trata-se de uma pesquisa qualitativa em que foram entrevistados 11 usuários, sistematizada por meio da análise de conteúdo do tipo análise temática. Os resultados apontam que a bicicleta compartilhada tem se tornado um meio de deslocamento alternativo ao transporte público deficiente, mas que seu papel como instrumento de lazer prevalece; encontrou-se a percepção de que o uso da bicicleta de forma contínua traz benefício à saúde, bem como a sensação de segurança. Todavia, há concentração de estações em poucos pontos da cidade e dificuldades de acesso em horário de pico. Conclui-se que o projeto de bicicletas compartilhadas no cenário deste estudo não contempla as demandas a elas atribuídas de mobilidade urbana; entretanto, fomenta o desenvolvimento de práticas corporais.
\end{abstract}

Palavras-chave: Mobilidade Urbana; Política Pública; Bicicleta; Práticas Corporais

1 Não houve conflitos de interesse para realização do presente estudo.

2 Graduado em Educação Física. Universidade Estadual do Ceará (UECE). Fortaleza/Ceará, Brasil.

E-mail: jpaulogurgel@yahoo.com.br

3 Mestre em Saúde Coletiva. Professor substituto da Universidade Estadual do Ceará (UECE). Fortaleza/ Ceará, Brasil. E-mail: brauliono08@homail.com

4 Graduado em Educação Física. Universidade Estadual do Ceará (UECE). Fortaleza/Ceará, Brasil.

E-mail: bergson.nogueira@hotmail.com

5 Doutorando em Ciências do Movimento. Professor auxiliar na Universidade Estadual do Ceará (UECE). Fortaleza/ Ceará, Brasil. E-mail: wellfitnesswell@gmail.com 


\section{INTRODUÇÃO}

O crescimento progressivo da população, assim como o aumento desordenado de veículos em grandes centros urbanos, são problemas da atualidade e, por essa razão, tem tomado destaque no cenário mundial, especificamente nas pautas de políticas públicas. Há de se falar até que o transporte e a mobilidade urbana são princípios essenciais do estado moderno de bem-estar e, dessa forma, considerados como valores importantes da sociedade (NIJKAMP; BLASS, 1994).

Essa grande valorização dos transportes ratifica-se quando as taxas de mobilidade são utilizadas como indicadores de desempenho de sistemas econômicos. Daí, surgem resultados positivos, mas negativos também são trazidos à tona, geralmente traduzidos pelo aumento excessivo da mobilidade e, consequentemente, pelo aumento no consumo de combustíveis, fator nocivo ao meio ambiente (NIJKAMP; BLASS, 1994).

Sendo assim, buscam-se alternativas de transportes que amenizem o problema de congestionamento das grandes cidades e, ao mesmo tempo, sejam opções mais sustentáveis. A utilização de bicicletas e o aumento das ciclovias são estratégias concebidas em regiões desenvolvidas e vêm sendo modelo para os países em desenvolvimento (GEIPOT, 2001).

No município de Fortaleza/CE, o Projeto Bicicletar, o qual segue o Sistema de Bicicletas Compartilhadas, modelo utilizado na maioria das capitais do Brasil, surgiu como iniciativa da Prefeitura e é patrocinada por uma cooperativa médica do Norte-Nordeste. Tem, como objetivo, incentivar o uso de transportes não motorizados e estimular a utilização de bicicletas como forma de prática de exercícios físicos (FORTALEZA, 2015).

O Sistema de Bicicletas Compartilhadas - que é um sistema presente na maioria das capitais do Brasil e é referência de mobilidade urbana em países desenvolvidos - é sinônimo de sustentabilidade, compartilhamento, coletividade, qualidade de vida, além de incentivar a prática de exercícios físicos (UNIMED, 2015).

Considerando a importância de instigar a população a utilizar outro meio de locomoção para seu deslocamento, o Projeto Bicicletar visa a incentivar a mobilidade urbana, à introdução do senso de compartilhamento e à melhoria da qualidade de vida da população, através de novos hábitos de prática corporal. Assim, o trabalho justifica-se pelos poucos estudos sobre o sistema recém-implantado na região, para se entender qual a repercussão do projeto nas práticas corporais da população e como essa proposta está possibilitando a melhoria da qualidade de saúde de seus usuários.

Diante disso, o presente trabalho tem por objetivo analisar as percepções dos usuários quanto à implantação do Projeto Bicicletar na cidade de Fortaleza. Para isso, buscamos descrever o contexto da mobilidade urbana, bem como as políticas públicas aplicadas às práticas corporais, além de apreender os aspectos motivacionais para o uso das bicicletas compartilhadas.

\section{METODOLOGIA}

A natureza desta pesquisa é qualitativa. Optou-se por um estudo qualitativo por considerar indispensável a análise em profundidade de um objeto complexo: as percepções quanto à implantação do Projeto Bicicletar na cidade de Fortaleza, já que se buscaram 
elementos não quantificáveis, bem como descrever características de ações ainda não identificadas.

O Projeto Bicicletar segue o modelo de Bicicletas Compartilhadas, que é um sistema presente na maioria das capitais do Brasil e é referência de mobilidade urbana em países desenvolvidos. Essa iniciativa da Prefeitura é patrocinada pela Unimed Fortaleza, cooperativa médica presente no Norte e no Nordeste do Brasil.

O projeto inicial prevê 40 estações e 400 bicicletas, sendo as 15 primeiras estações compostas de 150 bicicletas, inauguradas em 15 de dezembro de 2014. Sendo a estação 14 - Aterro de Iracema (Rua Rui Barbosa, esquina com Av. Beira-Mar, bairro Meireles, Fortaleza, Ceará) - a escolhida como local para entrevista. A seleção decorreu da proximidade da estação com as ciclovias elaboradas exclusivamente aos domingos pela Prefeitura de Fortaleza (Projeto Ciclofaixa de Lazer). Os pontos interditados em torno dessa estação proporcionam maior fluxo de usuários, dos mais diversos perfis, os quais preenchem os critérios de escolha dos participantes da entrevista.

Os participantes que se adequaram ao perfil da entrevista tiveram que estar cadastrados e ativos no sistema por, no mínimo, dois meses; de ambos os sexos, em idade potencialmente ativa, a qual, segundo o IBGE, configura-se na faixa etária entre 15 e 64 anos. Ao passo que foram excluídos da amostra aqueles que já praticavam regularmente o uso de bicicletas, visto que um dos objetivos foi observar a percepção dos usuários ocasionada em detrimento da implementação do sistema de compartilhamento de bicicletas. Participaram da pesquisa 11 sujeitos, quantidade em que as respostas dos usuários começaram se assemelhar. Os 11 participantes distribuíram-se em cinco mulheres e seis homens, com uma média de idade de 39 anos. A abordagem deu-se de forma aleatória àqueles que entregavam a bicicleta na estação ou que estavam estacionados.

A entrevista enquadrou-se como semiestruturada e, para isso, foi utilizado um roteiro de entrevista. Marconi e Lakatos (2010) classificam esses termos como instrumentos para o entrevistador desenvolver cada situação em qualquer direção que considere adequada e, para isso, existe um roteiro de tópicos no qual o entrevistado pode interagir da maneira que desejar. Esse roteiro foi composto por três questões que abordaram os motivos que levaram o usuário a utilizar o sistema de bicicletas compartilhadas, o que mudou nas suas práticas e a relação que o Projeto Bicicletar tem com a mobilidade urbana.

Segundo Minayo (2004), para alcançar os significados manifestos e latentes no material qualitativo, têm sido desenvolvidas várias técnicas. Um exemplo de técnica é a análise temática, a qual será utilizada nessa pesquisa. Esta técnica desdobra-se em três etapas: pré-análise, exploração do material e tratamento dos resultados obtidos e interpretação.

Na pré-análise, foram selecionados os documentos a serem analisados, retomados das hipóteses e dos objetivos iniciais da pesquisa, retificando-os frente ao material apurado; foram elaborados, outrossim, indicadores que orientem a interpretação final. Na segunda etapa, a exploração do material consiste, essencialmente, na operação de codificação. E a terceira etapa traduz-se no tratamento dos resultados obtidos e na interpretação através da identificação de núcleos de sentido propostos a demonstrar as percepções dos usuários quanto ao Projeto Bicicletar, conforme exposto no Quadro 1. 
Quadro 1 - Tema e núcleos de sentido emergente da pesquisa de campo, Fortaleza, 2015.

\begin{tabular}{|c|c|}
\hline Tema & Núcleo de sentido \\
\hline \multirow{3}{*}{$\begin{array}{c}\text { Percepções dos usuários } \\
\text { quanto ao Projeto Bicicletar. }\end{array}$} & Uso como transporte/ Rapidez no deslocamento. \\
\cline { 2 - 2 } & Acesso a bicicleta e o custo de utilização. \\
\cline { 2 - 2 } & Prática de exercício/ Cuidado com a saúde. \\
\cline { 2 - 2 } & Sensação de segurança. \\
\hline
\end{tabular}

Fonte: Elaborado pelo autor (2015).

Feito isso, o analista propõe conclusões previstas no seu quadro teórico ou abre possibilidades em torno de dimensões teóricas propostas pela leitura do material (MINAYO 2004). Assim, os resultados foram apresentados de acordo com os quatro núcleos de sentido emergentes.

A pesquisa foi realizada conforme a Resolução n 466, de 12 de dezembro de 2012, do Conselho Nacional de Saúde, que estabelece a eticidade da pesquisa em: autonomia, beneficência, não maleficência, justiça e equidade.

Uso como transporte/ rapidez no deslocamento

Nesse núcleo de sentido foi percebida entre alguns entrevistados a questão do uso da bicicleta numa perspectiva de celeridade de deslocamento pelo meio urbano e como esse tipo de transporte estava se mostrando uma nova opção de transporte para a população. Esse entendimento é visto nos discursos dos usuários 1, 3 e 10.

"A locomoção com a bicicleta é mais rápida [...]". (Usuário 1).

"[...] no dia a dia, meu filho usa muito para ir à faculdade [...]". (Usuário 3)

"[...] evitar utilizar transporte público e o automóvel em percursos de pequena e média distância. Acredito, sim, que facilitou, é um veículo que você percorre certas distâncias com muito mais velocidade que um veículo automotor". (Usuário 10).

Condizente com os achados, a concepção inicial do projeto era de ser realmente um meio de transporte de curto percurso, sendo a opção mais eficiente para deslocamento de até seis quilômetros. No entanto, a ideia da bicicleta como meio de deslocamento não foi consenso, possivelmente pela insuficiência de estações disponíveis ao público, ou mesmo pela forte cultura do veículo automotor, acrescida à diversão e ao prazer que a bicicleta proporciona, o que, aparentemente, dificulta torná-la mais bem vista nessa outra função.

O sistema de bicicletas compartilhadas é um meio sustentável de deslocamento, podendo, assim, ser considerado um transporte limpo e não poluente. O Usuário 4 comenta essa característica: "[...] utilizo buscando esquecer um pouco desses transportes que poluem mais a nossa cidade". 
Segundo Bostman e Rogers (2011), sistemas de compartilhamento, de qualquer tipo, fornecem benefícios ambientais significativos ao reduzir o desperdício e o excedente de produção e consumo. Porém, a sustentabilidade não é vista, muitas vezes, como motivação principal, mas como uma consequência não intencional.

A questão da rapidez das bicicletas no deslocamento complementa-se com opiniões sobre o trânsito e o transporte deficiente da cidade, apontados como causas para a preferência do deslocamento sobre duas rodas. Os usuários 6, 8 e 9 apresentaram as seguintes ideias a respeito:

"[...] é um meio mais rápido de chegar, ao invés de pegar um ônibus lotado, um trânsito gigante, a pessoa vai de bicicleta ali rapidinho e chega bem rápido". (Usuário 6).

"[...] mas, pelo o que eu vejo, muita gente vai para o trabalho, vai para a escola, já melhora a locomoção da pessoa, de passar muito tempo dentro de um ônibus, dentro de um carro.". (Usuário 8).

"[...] a mobilidade urbana, hoje em dia, está muito complicada, porque têm muitos carros, então a bicicleta entra num fator de facilitar; tanto que o pessoal que pega a bicicleta para ir para o trabalho chega até mais cedo, porque, se for de carro, pega muito engarrafamento. Então, é um passo muito importante para a população na questão da mobilidade [...]". (Usuário 9).

O uso das bicicletas do projeto como meio de transporte de forma mais rápida e como um meio de contornar o problema da mobilidade urbana surgiu de maneira muito presente, mostrando que os usuários acreditam que o programa possa suprir algumas das deficiências apresentadas pela atual conjuntura do transporte público em Fortaleza. Esse sistema de bicicletas compartilhadas surge como forma de complementar a demanda por novas formas de mobilidade nas grandes cidades, oferecendo um deslocamento mais rápido e prático. Muitos trabalhadores, tais como os policiais militares, não participam de práticas corporais devido a carga excessiva de trabalho (RODRIGUES; OLIVEIRA; SILVA, 2015), fato esse que pode ser parcialmente contornado ampliando o uso dessa ferramenta como forma de transporte.

O sistema de bicicletas compartilhadas tem bastante destaque em países como França, Dinamarca, Holanda, e representa uma fuga dos congestionamentos, assim como uma forma de aumento na qualidade de vida e de bem-estar. Para Reis (2012), esse sistema de compartilhamento é uma das formas mais inteligentes de contornar um dos maiores problemas das grandes cidades: o trânsito caótico, além de diminuir distâncias para quem teria que percorrer a pé longos trajetos.

Nesse sentido, Demaio e Gifford (2004) complementam que o sistema de bicicletas compartilhadas deve ser utilizado como um complemento ao sistema público de transporte, incentivando outros tipos de transporte público, facilitando a integração. Na perspectiva desses autores, quando as pessoas utilizam o serviço como um substituto para o ônibus, acabam não impactando necessariamente no trânsito da cidade ou na redução 
da poluição e, sim, trocando um tipo de transporte público por outro, em detrimento da integração desses meios.

Acesso à bicicleta e custo de utilização

Nesse ponto, os entrevistados ressaltam a praticidade e o fácil alcance às bicicletas compartilhadas. Dentre os principais argumentos, estão o baixo custo para o uso da bicicleta e a facilidade em encontrar as estações e em retirar as bicicletas, não tendo a mesma dificuldade de logística de sair com a sua bicicleta particular da residência para o local onde ocorreria a atividade, assim como destaca o usuário 7: "A facilidade, a praticidade de você ter à disposição quando quiser, não precisar transportar a bicicleta no seu carro".

A praticidade relacionada à bicicleta compartilhada relaciona-se ao fato de não precisarem de um espaço destinado em suas casas, à desobrigação de ser responsável e à facilidade de retirá-la e de devolvê-la em qualquer estação. Para os usuários que têm carro, a bicicleta é um substituto prático e fácil para o deslocamento em localidades sem muitas ofertas de vagas de estacionamento.

Outro aspecto inerente à praticidade é a autonomia que a bicicleta proporciona. Enquanto que para outros meios de transporte o usuário está sujeito a horários e trajetos definidos, a bicicleta está disponível e depende apenas da vontade do indivíduo, que dispõe de flexibilidade para trocá-la a qualquer momento por outro meio (BOSTMAN; ROGERS, 2011).

Vale salientar a estrita vinculação entre a percepção de facilidade de acesso e a proximidade das residências dos usuários às estações. É mais destacada aos que moram próximo, como é visto nos discursos dos entrevistados 2, 4 e 5.

"[...] como moro aqui perto da Beira Mar e minha bicicleta está velhinha, eu resolvi utilizar o sistema de bicicletas compartilhadas". (Usuário 2).

"[...] econômica, que acaba trazendo benefício e não sendo tão caro". (Usuário 4).

"A questão de não usar meu carro, ter uma estação próximo à minha casa". (Usuário 5).

Assim, é notável que a proximidade seja um fator motivacional importante para a utilização das bicicletas. Os usuários que não precisam de outro transporte complementar para o acesso da bicicleta como forma de transporte ou mesmo de lazer são mais suscetíveis ao uso. No entanto, percebe-se, principalmente nos dias de maior demanda na cidade, o fluxo maior de carros estacionados próximos às estações, ressaltando que a distância pode ser contornada pela prática.

Além disso, deve-se ressaltar que a mobilidade é afetada, além de tudo, pela distribuição das atividades, ou seja, quanto mais próximas dos locais de origem dos indivíduos, menor será a necessidade de qualquer transporte motorizado e mais opções de menor custo de deslocamentos serão utilizadas. 
Ainda com relação à infraestrutura, são levantadas questões sobre a falta de descentralização das estações pela cidade e sobre a quantidade de bicicletas, que ainda são insuficientes, principalmente nos horários de pico. Essas percepções são presentes nos discursos dos usuários 2 e 6.

"Aqui, no final de semana, eu acho legal, mas em outros bairros, com as ruas pequenas e sem estações, eu acho que está complicado". (Usuário 2).

"[...] vejo que, de manhã, muita gente vai do Benfica ao Centro e é impossível pegar bicicleta lá". (Usuário 6).

O Projeto Bicicletar ainda está em período inicial e conta com quantidade insuficiente de bicicletas para toda a cidade de Fortaleza. Segundo os idealizadores, as estações localizam-se em áreas estratégicas e tem como característica a alternativa de ser sistema de meio de transporte de curto percurso para facilitar o deslocamento das pessoas nos centros urbanos, todavia, os sujeitos do estudo apontam algumas dificuldades de acesso.

A cultura da bicicleta está crescendo e a tendência é que, com o passar do tempo, a quantidade de usuários também aumente. Assim, é importante que os responsáveis pelo Projeto fiquem atentos ao excesso de demanda e, desse modo, possam ofertar um serviço adequado à população. Entretanto, no momento, é difícil para os técnicos a monitoração e o abastecimento de forma contínua, ou seja, em um curto espaço de tempo.

Quanto ao baixo custo, Bostman e Rogers (2011) constatam que, além da vantagem ambiental que um serviço compartilhado apresenta, por não possuir a posse de fato do produto, o usuário não precisa arcar com o seu valor total. Ademais, encargos de propriedade, como consertos, manutenção ou seguro estão desvinculados da figura privada do usuário. Esse tipo de serviço proporciona liberdade e flexibilidade ao indivíduo, o qual fica livre para experimentar outras opções de serviço compartilhado.

\section{Prática de exercício e cuidado com a saúde}

Além da infraestrutura relacionada ao projeto, o bem-estar e a saúde são bastante presentes nos discursos. A opinião dos participantes da pesquisa é consensual quanto aos benefícios percebidos pela utilização da bicicleta, dentre os quais foram citados o bem-estar, opção de atividade para saída do sedentarismo e também como profilaxia para doenças crônico-degenerativas, como a hipertensão. As opiniões são percebidas nos discursos dos usuários 3, 4 e 6.

"[...] faço buscando o bem-estar, né (?), a saúde física [...]". (Usuário 3).

"[...] eu procuro mesmo a atividade física para, no futuro, não ter nenhuma dessas doenças aí que vem ocasionando no nosso mundo... Hipertensão, obesidade, pessoas morrendo tão cedo de infarto por falta de praticar e cuidar da sua saúde". (Usuário 4).

"Sair do sedentarismo, praticar atividade física no final de semana". (Usuário 6). 
A relação saúde e bicicleta aponta vinculação a uma terceira variável: a falta de tempo. Com o dia a dia corrido - e cada vez menos tempo para praticar atividade física -, o indivíduo identifica no ciclismo uma oportunidade de associar o exercício físico com o meio de transporte e com o lazer. O Projeto Bicicletar proporciona às pessoas uma atividade de forma prazerosa e divertida, de maneira prática, pois não exige que o usuário saia de casa com uma bicicleta, e ainda tem a liberdade de fazer outros programas sem ter a preocupação com a bicicleta.

O perfil dos usuários com relação às práticas corporais é variado, apresenta os que saíram do sedentarismo e passaram a praticar o ciclismo como exercício físico e os que já mantinham uma atividade física regular e agregaram o ciclismo às suas atividades corporais, como o usuário 8: "[...] porque sábado e domingo são os únicos dias que eu não pratico atividade física, e, para não ficar parada, eu resolvi andar de bicicleta. [...] Em vez de praticar atividade física só de segunda a sexta, agora tenho uma atividade todo dia".

Vale destacar que a maioria dos usuários afirma não ter o hábito de pedalar antes da implantação do projeto.

A prática do ciclismo como atividade física - e, por conseguinte, os benefícios advindos dele - é um dos objetivos principais do Projeto Bicicletar e vem alcançando êxito, como mostram os discursos dos entrevistados. Em sua maioria, os indivíduos demonstram acreditar na eficiência dos benefícios que o ciclismo proporciona. Todavia, os benefícios devem ser verificados em longo prazo, tendo em vista que o sistema ainda está no início e não há como averiguar os resultados de forma consistente. Além disso, estudos como o de Ferreira, Oliveira e Sampaio (2013) identificaram que a concepção de saúde fomentada no campo da Educação Física escolar, por exemplo, é restrita a aspectos individuais e biológicos, ao deixar de maneira obscura aspectos psicossociais.

De acordo D'Elia (2009), o sucesso do ciclismo se dá pelo entusiasmo que essa forma de atividade gera nos praticantes, devido à harmonia que há entre o homem e bicicleta, como uma extensão do próprio corpo. Além disso, destaca-se a versatilidade que esse meio carrega em sua essência, adaptando-se aos vários ambientes que o meio urbano proporciona ao ciclista, passando de meio de transporte ao lazer.

Sensação de segurança

Esse núcleo de sentido, a princípio, não estava incluso no trabalho, tendo em vista que essa temática não fez parte das temáticas investidas no roteiro de entrevista. Entretanto, por ser um tema emergente do material empírico, e, portanto, significativo, foi aqui incluído.

Duas são as perspectivas em que a segurança está inserida: a segurança no trânsito e a violência urbana. Na primeira, mencionam-se as ciclofaixas e o comportamento dos motoristas diante da utilização delas. E a segunda refere-se à sensação de insegurança dos entrevistados quando estão pedalando com sua bicicleta particular.

A maior demanda de uso das bicicletas compartilhadas ocorre nos domingos por conta do trânsito durante os dias úteis. Além de ser o dia de descanso da maioria da população, também é o dia que comtempla as ciclofaixas de lazer, que contam com sinalizações temporárias em alguns pontos da cidade, além da presença de agentes de 
trânsito, que garantem a segurança de quem pedala. Assim, é evidenciado o temor dos usuários em utilizar as bicicletas de forma constante, em outros locais e em outros dias da semana. Esse receio é expresso pelo usuário 11.

\footnotetext{
"Eu procuro justamente no final de semana por causa da ciclofaixa de lazer..., e você acredita que final de semana passado fui até o Eusébio pela ciclofaixa(?); deixa a gente mais tranquila por causa do trânsito, na semana não me sinto muito segura de andar nas ciclofaixas; quando vou andar, eu procuro ir nos horários que são menos movimentados, mas é muito bom". (Usuário 11).
}

Alguns entrevistados apontam o fator cultural da população como justificativa do despreparo da cidade de receber um projeto dessa natureza. Segundo Freitas e Vieira (2007), em países cujo tipo de transporte já é bem popular e com infraestrutura de trânsito mais adaptada, a população é educada a respeitar e ter uma convivência harmônica entre todos os tipos de transporte.

Há muitas ações que ainda devem ser tomadas para que o uso da bicicleta se torne um hábito para a população de nosso país, tais como investimentos em infraestrutura viária nas cidades, campanhas de trânsito incentivando o uso da bicicleta, engajamento dos profissionais de saúde e até mesmo a inclusão da disciplina de ciclismo no currículo dos cursos de Educação Física (FREITAS; VIEIRA 2007). Então, para a manutenção de uma cidade sustentável, Carruthers e Lawson (1995) propõem que a mobilidade deve ser conduzida de forma a permitir a coexistência de diferentes formas de viagens.

No que diz respeito à violência urbana, cita-se como vantagem o fato do indivíduo não possuir privadamente a bicicleta, o que reduz a possibilidade de assaltos. O usuário 1 exprime esse receio: "[...] com a bicicleta particular se corre o risco de uma agressão devido a insegurança e, com a compartilhada, não".

As bicicletas do projeto são projetadas de forma especial, possuindo peças específicas para o modelo de bicicleta eleito pela proposta. Assim, evita-se o desmonte não autorizado das bicicletas a fim de repasse para outros modelos.

Vale ressaltar, outrossim, o fato de os entrevistados não mencionarem a questão da vulnerabilidade do uso do celular como opção para a liberação das bicicletas das estações. Os usuários podem ligar ou utilizar o aplicativo nos smartphones para acessar as bicicletas, estando sujeitos a assaltos.

\section{CONSIDERAÇÕES FINAIS}

A concepção da bicicleta como meio de transporte ainda está sendo construída pelos indivíduos. Apesar da menção da bicicleta como um novo meio de deslocamento e de suprir as deficiências do transporte público da cidade, os usuários entrevistados não foram convictos de que esse instrumento possa se encaixar no papel de locomoção. Os veículos automotores têm um grande destaque na cultura da cidade, por isso, ainda é custosa a visão geral da bicicleta como meio de transporte. 
Com relação à infraestrutura, os usuários apontaram a concentração das estações pela cidade e o excesso de demanda pelas bicicletas como pontos negativos do projeto, opinião menos presente aos que residiam próximo às estações, ao passo que a praticidade e a flexibilidade foram fortes fatores motivacionais apresentados. Os principais argumentos foram a não necessidade de um espaço nas suas casas reservado à bicicleta e por ela ser um prático substituto no deslocamento em locais de difícil estacionamento. Dessa forma, pode-se inferir que a proximidade é motivo determinante para uso das bicicletas; quanto mais próximas as estações, menor a necessidade de outro transporte motorizado.

O perfil dos usuários se mostrou variado, verificam-se usuários que já praticavam outras práticas corporais e identificaram na bicicleta compartilhada um complemento, assim como se percebeu a presença de usuários que saíram do sedentarismo com o ciclismo. De forma geral, os indivíduos demonstraram acreditar na eficiência dos benefícios que a atividade proporciona.

Ademais, este trabalho propõe aos idealizadores do sistema de bicicletas compartilhadas o aumento do alcance a outras regiões da cidade e a expansão das estações nos pontos de maior demanda; além de medidas que visem a maior integração entre as bicicletas compartilhadas com os demais meios de transporte da cidade, e um maior investimento para que a bicicleta possa ter condições mais adequadas de existir na cidade.

\section{REFERÊNCIAS}

BOSTMAN, R; ROGERS, R. O que é meu é seu. Como o consumo colaborativo vai mudar o nosso mundo. Porto Alegre: Bookman, 2011.

CARRUTHERS, D.; LAWSON, G. (1995). The contribution of transport to the quality of life. In: BLESSINGTON, H.K, ed. Urban Transport. London, Thomas Telford. P.11-20. D’ELIA, J. R. Ciclismo: treinamento, fisiologia e biomecânica. São Paulo: Phorte, 2009.

DEMAIO. P.; GIFFORD J. W. Smart bikes succeed as Public Transportation in The Unites States? Journal of Public Transportation, London v. 57, n.1, p.9-11, may, 2004.

FERREIRA, H. S.; OLIVEIRA, B. N.; SAMPAIO, J. J. C. Análise da percepção dos professores de Educação Física acerca da interface entre a saúde e a Educação Física escolar: conceitos e metodologias. Rev. Bras. Ciênc. Esporte, Porto Alegre, v. 35, n. 3, p. 673-685, Set. 2013 .

FORTALEZA. Transportes. 2015. Disponível em: < http://www.fortaleza.ce.gov.br/servicos/ Cidadão/Transporte $>$. Acesso em: 02 abr. 2015.

FREITAS, A.; VIEIRA, S. O que é ciclismo: história, regras, curiosidades. Rio de Janeiro: Casa da Palavra: COB, 2007.

GEIPOT. Manual de Planejamento Cicloviário. Empresa Brasileira de Planejamento de Transportes. Brasília, DF: Ministério dos Transportes, 2001.

MARCONI, M.A.; LAKATOS, E.M. Fundamentos de metodologia científica. 7. Ed. São Paulo: Atlas, 2010.

MINAYO, M. C. S. O desafio do conhecimento: pesquisa qualitativa em saúde. 8. ed. São Paulo: Hucitec, 2004. 
NIJKAMP, P.; BLAAS, E. (1994). Impact assessment and evaluation in transportation plannin. Dordrecht, The Netherlands, Kluwer Academic Publishers.

REIS, M. E. Memorial de projeto de pesquisa fotorreportagem: Brasília dá Pedal - a cultura da bicicleta no Distrito Federal. Brasília, 2012.

RODRIGUES, D. C.; OLIVEIRA, B. N.; SILVA, A. L. F. Saúde do trabalhador e qualidade de vida: experiência em um batalhão de Polícia Comunitário do sertão cearense. Motrivivência, Florianópolis, v. 27, n. 44, p. 142-149, mai. 2015.

UNIMED (Fortaleza). Bicicletas compartilhadas. 2015. Disponível em: < http://www. unimedfortaleza.com.br/portal/bicicletar_principal.html>. Acesso em: 02 abr. 2015.

PUBLIC POLICIES OF URBAN MOBILITY AND PHYSICAL EXERCISES: repercussions of bike-sharing systems

\section{ABSTRACT}

The study sought to examine the perceptions of users regarding the implementation of bike-sharing systems in Fortaleza, Ceará. This qualitative study interviewed 11 users, and systematization of data through thematic analysis of content analysis. The results indicate that the bike-sharing systems has become an alternative means of transportation, but its role as a leisure instrument prevails; He met the perception that the use of continuously cycling brings health benefits and a sense of security. However, the project is in a few places in the city and with limited access at certain times. We conclude that the shared bicycle system does not address the needs of urban mobility; however, it enhances the development of physical exercise.

Keywords: Urban Mobility; Public Policies; Bicycle; Corporal Practices

\section{PUBLIC POLICIES SOBRE LA MOVILIDAD URBANA Y EJERCICIO FíSICO: los efectos del sistema de bicicletas compartidas}

\section{RESUMEN}

El estudio trató de examinar las percepciones de los usuarios en relación con la implementación de sistemas de bicicletas compartidas en Fortaleza, Ceará. Este estudio cualitativo entrevistó a 11 usuarios, y la sistematización de los datos a través del análisis temático de análisis de contenido. Los resultados indican Que los sistemas de bicicletas compartidas se ha convertido en un medio alternativo de transporte, pero su papel como instrumento de ocio prevalece; Se reunió con la percepción de que el uso de la bicicleta continuamente trae beneficios para la salud y una sensación de seguridad. Sin embargo, el proyecto se encuentra en unos pocos lugares en la ciudad y con acceso limitado a ciertas horas. Llegamos a la conclusión de que el sistema de bicicletas compartidas no se ocupa de las necesidades de movilidad urbana; Sin embargo, se potencia el desarrollo del ejercicio físico.

Palabras clave: Movilidad Urbana; Políticas Públicas; Bicicleta; Práticas Corporales 